\title{
Is guanxi unfair? Market reform and the public attitude toward guanxi in urban China
}

Felicia F. Tian(D)

\author{
Correspondence: ftian@fudan.edu. \\ cn \\ Department of Sociology, Fudan \\ University, 220 Handan Road, \\ Yangpu District, Shanghai 200433, \\ China
}

\begin{abstract}
Guanxi is a fundamental, but controversial, feature of Chinese society. This article examines public attitudes about the fairness of guanxi and how Chinese market reform is affecting these attitudes. The reciprocity-laden and tie-sensitive nature of guanxi conflicts with the efficiency-oriented goal of a market economy. Disapproval of guanxi is thus increasing as marketization progresses. Results from the 2008 Chinese General Social Survey show that guanxi is more likely to be viewed as unfair in places with higher levels of marketization. The educational gradient decreases with marketization, and change is more pronounced among people working in the market sector than it is among people working in the state sector. My findings suggest that Chinese market reform increases public disapproval of guanxi.
\end{abstract}

Keywords: Guanxi, Chinese market reform, Public attitude, Fairness, Education, Employment sector

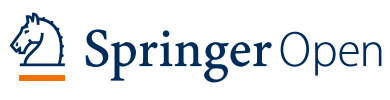

\section{Introduction}

Guanxi is a foundational system of transactional social ties in China that have a strong emotional foundation based on kin and pseudo-kin relationships (Barbalet 2014; Bian and Zhang 2013; Luo 2011). Guanxi emphasizes obligations and reciprocity, and it is a fundamental feature of Chinese society (Yang 1994). Since China's post-1978 market reform, the significance of guanxi and the future of it in the economy has been the subject of extensive debate (for a review, see Bian 2018). Quantitative studies have documented a consistent increase in the use of guanxi in the Chinese labor market since the 1980s (Bian 2002; Tian and Lin 2016; Zhang and Guo 2011; Zhang and Cheng 2012; Zhang and Zhang 2012; Zhao 2013). This increase has led scholars to depict a model of "network capitalism" (Boisot and Child 1996), wherein guanxi promotes the exchange of favors, enhances trust, and reduces uncertainty (Nee and Opper 2012; Yeung and Tung 1996). Yet, network scholars interpret this trend with caution, noting that guanxi practices have evolved along with the market reform to focus less on backchannel negotiations and more on social capital, such as weak ties and brokerage for

(c) The Author(s). 2021 Open Access This article is licensed under a Creative Commons Attribution 4.0 International License, which permits use, sharing, adaptation, distribution and reproduction in any medium or format, as long as you give appropriate credit to the original author(s) and the source, provide a link to the Creative Commons licence, and indicate if changes were made. The images or other third party material in this article are included in the article's Creative Commons licence, unless indicated otherwise in a credit line to the material. If material is not included in the article's Creative Commons licence and your intended use is not permitted by statutory regulation or exceeds the permitted use, you will need to obtain permission directly from the copyright holder. To view a copy of this licence, visit http://creativecommons.org/licenses/by/4.0/. 
information exchange, which are also typical of Western market economies (Burt and Burzynska 2017; DiTomaso and Bian 2018; Lin et al. 2013; Tian and Lin 2016).

So far, few researchers have systematically examined public attitudes toward the fairness of guanxi and whether such attitudes have changed since the post-1978 market reform. Public attitudes toward guanxi involve a shared knowledge of institutional contexts that provides a legitimate basis for social actions (Berger and Luckmann 1966; Douglas 1986). The key to understanding the guanxi dilemma is determining whether it violates principles of justice and fairness (Dunfee and Warren 2001). If the public views guanxi as unfair, people may not want to use guanxi or at least acknowledge using it for the exchange of favors because it is hard to justify that practice. Thus, understanding public attitudes toward the fairness of guanxi may have important implications for the future of guanxi in Chinese society.

Existing research indicates that guanxi is indeed morally controversial (Yang 1994). For example, some research on samples of firm managers indicates that they find guanxi morally contemptible (Su et al. 2003; Warren et al. 2004). A few qualitative interviews of college students and managers likewise reveal increasing resistance to guanxi during the market reform era (Guthrie 1998; Hanser 2002; Huang 2008). However, the limited scope of these research samples undermines the robustness and generalizability of these studies.

This article uses data from the 2008 Chinese General Social Survey (CGSS) to show how the Chinese view the fairness of guanxi and to test whether these views are associated with the degree of marketization that has been reached. The results suggest that guanxi is increasingly viewed as unfair in places with higher levels of marketization. Individual characteristics, such as educational attainment and employment sector, also affect the negative association between marketization and the perceived fairness of guanxi.

\section{Theoretical Background and Hypotheses}

\section{Guanxi in reform-era China}

Many agree that guanxi is ingrained in Chinese culture (Hwang 1987; Yan 1996; Yang 1994). It eases social interactions and gives "the flow of many events a helping hand" (Zuo 1997, 69). Building and maintaining guanxi are critical for personal advancement and business success in China (Alngenberg 2008; Bian and Huang 2009; Burt and Burzynska 2017; Keister 2002; Luo et al. 2012; Yeung and Tung 1996). In several situations, building guanxi surpasses economic transactions as the main purpose of business interactions (Lin 2002).

The post-1978 reform has led to guanxi having increasing significance in the labor market, particularly in terms of its implications for job mobility. Bian (2018) has estimated that the proportion of jobs found through guanxi, as measured by network influence, nearly doubled from 1978 to 2009 . Less than $40 \%$ of jobs were found through guanxi in 1978, compared to almost $80 \%$ in 2009. Tian and Lin (2016) have studied job mobility and have found that the use of guanxi, as measured by the use of kinship ties or very close ties, increased from about 10 to 20\% between 1978 and 2008. Yet, guanxi may not always lead to better jobs (Obukhova 2012; Obukhova and Lan 2013; Obukhova and Zhang 2017), and the returns from it have declined somewhat (Zhang and Cheng 2012; Zhang and Zhang 2012). Still, quantitative research consistently highlights the growing significance of guanxi in the reform-era labor market (Bian 2018). 
This rising significance of guanxi does not guarantee its moral legitimacy, however. Qualitative interviews with managers indicate that fairness remains a major concern in their views about the practice. Although Chinese managers view guanxi as a helpful system, they also believe it can undermine the competitiveness of corporations and the health of the business environment (Su et al. 2003; Warren et al. 2004; Yeung and Tung 1996). Managers tend to shy away from guanxi when discussing their corporate strategies, because it is perceived as illegal and is associated with corruption and bribery (Guthrie 1998; Hwang et al. 2009), and because it reduces trust in management (Chen et al. 2004).

The general public also believes that guanxi may violate fairness. For example, Yang (1994) has vividly captured Chinese perceptions of the coercive and objectionable nature of guanxi in the 1980s, when marketization had just begun. Some Chinese agreed that guanxi can help achieve a reasonable objective when other paths are blocked, but others viewed it as morally objectionable, aberrant, based on self-interest, and treacherous for social interactions. They equated guanxi with "badness," "deception," and "harm to society." As one interviewee said, "Guanxi(xue) is when you treat someone differently than you otherwise would because of how much that person is of use to you. Guanxi(xue) is not upright; it is crooked and sly" (Yang 1994, 51).

The degree to which public attitudes about the fairness of guanxi may have changed since the Chinese market reform has never previously been tested with quantitative data. Bian (2018) has called for more empirical analyses of the extent to which guanxi ties grow or decline in relation to the rise of market economy in China, and under what conditions. A few studies based on qualitative interviews have implied that guanxi practices may decline with the rise of the market economy. For example, in interviews with managers at large, state-owned enterprises in Shanghai, Guthrie (1998) has shown that they reject guanxi practices in recruitment and consider them unnecessary in market transactions. In contrast, Huang (2008) has found that guanxi remained prevalent in state-sector organizations during the reform era. However, as these studies are based on small-scale, nonprobability samples, the findings are not generalizable (Bian 2018). Furthermore, although most people practice guanxi, few admit to it publicly, so the results from qualitative interviews must be interpreted with caution (Yang 2002). To address this question, this study uses a national representative sample from urban China.

\section{Market economy and fairness of guanxi}

The classic literature identifies three rules (equity, equality, and need) that define the fairness of an exchange (Deutsch 1975; Greenberg and Cohen 1982). The equity rule encourages distribution of resources according to relative contribution. The equality rule dictates that resources should be distributed equally regardless of one's contribution. The need rule suggests resources should be distributed according to individuals' legitimate needs, regardless of their contribution. Each rule finds legitimacy in certain institutional contexts. For example, the equity rule is legitimate in situations that emphasize productivity and efficiency; the equality rule is legitimate in situations that emphasize cooperation and harmony; and the need rule is legitimate in situations that emphasize social welfare and personal growth (Deutsch 1975; Ritzman and Tomaskovic-Devey 1992). 
A market economy legitimizes the equity rule through the perception of the fairness of an exchange. Market exchange requires the distribution of resources and rewards to reflect the scarcity and importance of goods and skills (McClosky and Zaller 1984). It promotes competition and tolerates inequality, as long as achievement is positively associated with contribution (Ritzman and Tomaskovic-Devey 1992; Roller 1994). Exchanges that emphasize productivity and efficiency rely on abstract principles that are not contingent on relations or situations (Kohlberg 1981). In contrast, guanxi endorses a renqing rule, which highlights reciprocity and indebtedness as the means of maintaining harmony in a hierarchical social order (Hwang 1987). The Chinese structure personal relations according to familiarity and adopt multiple standards when interacting with people in different social circles (Fei 1947; Hsu 1953). Thus, the renqing rule is particularistic; it changes in proportion to the strength of relations between actors (Tan and Snell 2002; Yang 1994). The obligation of reciprocity is "heavily shaped by the hierarchically structured network of guanxi in which one is involved, by the long time period over which these relations are expected to last, and by the public nature of the obligations incurred in continuing exchanges" (Hwang 1987, 968).

Renqing differs from equity in two major ways. First, renqing is particularistic, whereas equity is universalistic. Renqing operates exclusively on specific types of ties in which both parties have something in common, maintain emotional attachment, and help one another in anticipation of future returns (Bian 2018; Hwang 1987). In contrast, equity operates on abstract principles and is not tie-sensitive: both parties in an exchange perceive each other as role occupants rather than as specific individuals (Ellard et al. 2016). Second, renqing highlights reciprocity, whereas equity emphasizes efficiency. In an exchange, the obligation of reciprocity implies that one should not allocate rewards based on performance or contribution but should instead prioritize network members or those with previous exchange experience (Barbalet 2015; Luo 2011). In contrast, when efficiency is emphasized, individual performance and contributions are rewarded in order to increase productivity (Lerner 1977).

One caveat needs to be mentioned here. During the 1950s and 1960s, the Communist Party of China (CPC) progressively denounced guanxi (Li and Tian 2020) and instead proposed universal egalitarianism (Vogel 1965). Yet, the state-controlled, top-down allocation of resources necessitated the tacit continuation of the renqing rule. In the socialist economy, resources had to be distributed through bureaucratic procedures, which were overseen by a relatively small number of government officials (Kornai 1992). This resource distribution system created a system of party clientelism requiring people to build relationships with officials and exchange their political loyalty for material and symbolic rewards (Gold 1985; Walder 1986). Guanxi became a necessary and somewhat coercive way to "bypass officially sanctioned, and onerous, bureaucratic procedures, solicit protection from more powerful actors, and acquire otherwise unavailable resources" (Chang 2011, 316)

I argue that a market economy should undermine the legitimacy of guanxi. Kluegel et al. (1995) have provided a comprehensive comparison of the fairness principle using a standard questionnaire administered in 22 countries in 1990 and 1991, right after the collapse of the Soviet Union. They have found that people in market economies endorse equity, whereas people in post-socialist economies endorse equality. Yet, a swift shift to equity occurred in the transition from a socialist to a market economy. Within 
one year of the unification of East and West Germany, East Germans endorsed the equity principle to a degree close to the degree to which Western Germans endorsed it (Roller 1994). Thus, because actors in a market exchange prioritize equity, Chinese people undergoing marketization may view the reciprocity-bound, particularistic renqing rule of guanxi as unfair.

\section{Hypotheses}

Since the 1980s, China has transformed from a planned economy to a market economy. The shift to a market economy could facilitate changes in people's beliefs about fairness, which in turn could alter their attitudes toward guanxi. Indeed, visible signs of attitudinal changes (e.g., promoting equity and legitimizing inequality) appeared early in the reform era. Official slogans, for example, included "Time is money, efficiency is life [shi jian jiu shi jin qian, xiao lv jiu shi sheng ming]" and "Let some people get rich first [rang yi bu fen ren xian fu qi lai]" (Naughton 2006). Two national surveys in 2004 and 2009 by Whyte (2009) have shown that Chinese beliefs about fairness differed greatly from their beliefs during the socialist era and instead began to resemble those endorsed by Americans or Europeans. Furthermore, the Chinese tolerated the rising income inequality because they believed in hard work and were optimistic about their chances for upward mobility (Whyte and Im 2014). These findings imply a shift in public preference to the equity rule. As guanxi conflicts with the equity rule, it also becomes less legitimate. I thus propose the following hypothesis:

Hypothesis 1: As marketization increases, guanxi is more likely to be viewed as unfair.

The relationship between marketization and public attitudes about guanxi practices and fairness may vary according to one's education. Chinese people with college educations often prefer meritocracy and oppose the use of guanxi in job searches (Hanser 2002; Meng 2012). Sun (2009) has shown that an education-related bifurcation in Chinese public beliefs about fairness occurs along with market reform: people with college educations increasingly endorse meritocracy and equity, whereas people without college degrees stick firmly to the equality principle. I thus argue that college-educated people may be more affected by the contextual level of marketization than those with less education. Specifically, I hypothesize the following:

Hypothesis 2: The negative relationship between marketization and attitudes about the fairness of guanxi are stronger among the college educated than among the less educated.

Employment sector may be another important moderator. Guanxi prevailed in hiring decisions within the state sector during socialism (Walder 1986), and it has continued to be critical during the marketization process (Nee 2005; Nee et al. 2007). Despite ambitious legal efforts to reform the state sector, new laws and regulations have not yet been enacted in practice (Nee 2005). The informal decision-making embedded in party-controlled networks thus continues to prevail (Nee and Opper 2010). In contrast, those working in the market sector may be more affected by the contextual level of 
marketization than those working in the state sector. During the early stages of reform when resources were still monopolized by the state and rules were unclear, guanxi was necessary and beneficial in the market sector to navigate ambiguous situations and gain access to critical resources (Wank 2001; Xin and Pearce 1996). As the reform progressed, however, the significance of guanxi declined (Nee and Opper 2010; Nee et al. 2007). This insight shapes my third hypothesis:

Hypothesis 3: The negative relationship between marketization and attitudes about the fairness of guanxi are stronger among those working in the market sector than in the state sector.

\section{Data and methods \\ Data}

Data used in this research came from the 2008 CGSS (http://www.cnsda.org/). Started in 2003, the CGSS is a national, representative, and repeated cross-sectional household survey of noninstitutionalized Chinese adults aged 18 to 69 years. It provides rich information on socioeconomic status, life events, and quality of life in this rapidly changing society. The CGSS sample is stratified in a four-stage sampling scheme, separated into urban and rural areas (Bian and Li 2012). The 2008 wave is the only one that collected public attitudes about guanxi. In this study, the analysis is restricted to the urban sample and respondents who were not farmers at the time of the survey. The sample size, with complete information on dependent, independent, and control variables, is 3628 .

\section{Methods}

\section{Public attitudes about the fairness of guanxi}

The CGSS asks respondents to assess the statement "Using guanxi to do things does not violate fairness (strongly agree, agree, neutral, disagree, strongly disagree, and hard to say)." Very few people answered "strongly agree" or "strongly disagree." I therefore use a three-level indicator of respondents' attitudes (fair, neutral, or unfair). Answers are coded 1 if respondents viewed guanxi as fair (by answering "strongly agree" or "agree"); they are coded 2 if respondents viewed guanxi as neutral (by answering "neutral" or "hard to say"); and they are coded 3 if respondents viewed guanxi as unfair (by answering "strongly disagree" or "disagree").

\section{Independent and control variables}

\section{Marketization score (provincial level)}

I use an index of the development of the non-state economy created by Fan et al. (2011) to measure marketization at the provincial level. This index includes three components: (1) industrial value-added, (2) investment, and (3) urban employment. Each province receives a numeric score indicating the development of its market economy, relative to other provinces. A higher value means a higher level of development. I use the 2007 indicator (1-year lag), ranging from 3.12 to 13.44, with Gansu province at the bottom and Jiangsu province at the top. Three provinces (Qinghai, Tibet, and Hainan) are dropped from the analysis because they were not surveyed in the CGSS. 


\section{Educational attainment (individual level)}

Educational attainment is measured as the highest level of schooling attained, classified into three categories. Respondents who had no education, or who had a primary school or junior high school education, are coded as having a junior high education or below (reference group); those who had a senior high school education, a senior vocational school education, or a junior technical school education are coded as having a senior high education; and those who had associate's, bachelor's, master's, or doctoral degrees are coded as having a college education or above.

\section{Market-sector employment (individual level)}

Market-sector employment is a dummy variable indicating whether the respondent worked in the market sector. It is coded as 1 if respondents worked in private firms, foreign-owned firms, or joint ventures and as zero if respondents worked in government agencies, public institutes, or state-owned firms.

Individual-level control variables include gender, cohort, Communist Party membership, occupation, marital status, migration status, and region. Gender $(1=$ female, $0=$ male), Communist Party membership ( $1=$ party member, $0=$ not $)$, marital status $(1=$ currently married, $0=$ currently not married $)$, and migration status $(1=$ migrants, $0=$ residents) are measured as dummy variables. Cohort is measured as the year respondents reached age 20 (prior to 1978, 1978-1992, 1993-2001, or 2002-2008), corresponding to the pre-reform, dual-track system, rapid privatization, and post-WTO periods, respectively (Bramall 2009; Tian and Lin 2016). Occupation is classified into white-collar (managers, professionals, technicians, and clerks), blue-collar (service, sales, and production workers), or not working (reference group). Region is coded as east (reference group ${ }^{1}$ ) middle, ${ }^{2}$ or west $^{3}$ and is included because in addition to marketization, Chinese attitudes about fairness and inequality vary by region (Whyte 2009). Table 1 shows the descriptive statistics of independent and control variables.

\section{Multi-level ordinal logistic regression}

I apply multi-level, ordinal, logistic regression to examine the likelihood of viewing guanxi as fair, neutral, or unfair. This random-intercept model of individuals is clustered within provinces. The level 1 predictors include individual-level controls. The level 2 predictors include the provincial-level private economic development scores, which indicate a province's marketization level. The multilevel, multiple equation notion is

$$
\begin{aligned}
& \mathrm{y}_{\mathrm{ij}}=\beta_{0 \mathrm{j}}+\sum_{k=1}^{w} \beta_{k j} \mathrm{~W}_{k j}+\gamma_{\mathrm{ij}} \\
& \beta_{0 \mathrm{j}}=\gamma_{00}+\gamma_{01} \mathrm{Z}_{\mathrm{j}}+\mathrm{u}_{0 \mathrm{j}}
\end{aligned}
$$

\section{Thus,}

\footnotetext{
${ }^{1}$ Provinces in the eastern region include Beijing, Liaoning, Hebei, Shandong, Shanghai, Jiangsu, Zhejiang, Fujian, and Guangdong.

${ }^{2}$ Provinces in the middle region include Jilin, Heilongjiang, Inner Mongolia, Shanxi, Henan, Anhui, Jiangxi, Hunan, and Hubei.

${ }^{3}$ Provinces in the western region include Xinjiang, Gansu, Shaanxi, Ningxia, Sichuan, Guizhou, Yunnan, and Guangxi.
} 
Table 1 Mean statistics (unweighted) of independent and control variables

\begin{tabular}{|c|c|}
\hline & Mean \\
\hline Female & 0.512 \\
\hline \multicolumn{2}{|l|}{ Cohort } \\
\hline$<1978$ & 0.278 \\
\hline 1978-1992 & 0.333 \\
\hline $1993-2001$ & 0.209 \\
\hline $2002-2008$ & 0.180 \\
\hline \multicolumn{2}{|l|}{ Education } \\
\hline$\leq$ Junior high & 0.450 \\
\hline Senior high & 0.314 \\
\hline$\geq$ College & 0.236 \\
\hline Party member & 0.145 \\
\hline Currently married & 0.775 \\
\hline Migrants & 0.222 \\
\hline \multicolumn{2}{|l|}{ Occupation } \\
\hline White-collar workers & 0.343 \\
\hline Blue-collar workers & 0.576 \\
\hline Not working & 0.081 \\
\hline Market sector employment & 0.469 \\
\hline \multicolumn{2}{|l|}{ Region } \\
\hline East & 0.419 \\
\hline Middle & 0.360 \\
\hline West & 0.221 \\
\hline Number of cases & 3628 \\
\hline Marketization score & $8.403(2.622)$ \\
\hline Number of provinces & 28 \\
\hline
\end{tabular}

Standard deviation in parentheses

$$
\mathrm{y}_{\mathrm{ij}}=\gamma_{00}+\gamma_{01} \mathrm{Z}_{\mathrm{j}}+\sum_{k=1}^{w} \beta_{k j} \mathrm{~W}_{k j}+\mathrm{u}_{0 \mathrm{j}}+\gamma_{\mathrm{ij}}
$$

where $\mathrm{W}_{\mathrm{kj}}$ denotes individual-level controls and $\mathrm{Zj}$ denotes the provincial-level marketization score. In this model, each individual's likelihood of viewing guanxi as fair, neutral, or unfair is composed of three elements: the overall mean $\left(\gamma_{00}\right)$, the deviation of the cluster mean from the overall mean $\left(\mathrm{u}_{0 \mathrm{j}}\right)$, and the deviation of an individual's likelihood from the cluster mean $\left(\gamma_{i j}\right)$. The value of $u_{0 j}$ is assumed to vary randomly across provinces, with a mean of zero and a variance of $\tau_{00}$. $\gamma_{01}$ represents the unit change in the predicted value of the intercept per unit of change in the province-level marketization score.

To examine whether the association between marketization and guanxi attitudes varies by education (or employment sector), I add the interaction between education (or employment sector) and marketization score as follows:

$$
y_{i j}=\gamma_{00}+\beta_{1} X_{j}+\gamma_{01} Z_{j}+\beta_{2} X_{j} * Z_{j}+\sum_{i=3}^{w} \beta_{i j}+W_{i j}+u_{0 j}+\gamma_{i j}
$$


$X_{j}$ denotes individual-level educational level (or employment sector), and $X_{j} ; Z_{j}$ denotes the interaction between education level (or employment sector) and marketization score.

\section{Results}

\section{Diverging public attitudes about guanxi}

Figure 1 plots public attitudes with regard to the statement "Using guanxi to do things does not violate fairness." Urban Chinese diverged significantly, as $33.08 \%$ of respondents viewed guanxi as fair, compared with $19.01 \%$ of respondents who viewed it as neutral and $47.85 \%$ of respondents who viewed it as unfair. The following regression models compare these three groups.

\section{Marketization and public attitudes about guanxi}

Table 2 reports coefficients from the multi-level, ordinal, logistic regressions predicting whether guanxi practices is viewed as fair, neutral, or unfair. Model 1 includes individual-level controls and the provincial-level marketization score. The likelihood ratio test between multi-level ordinal logistic regression and ordinal logistic regression suggests that the former is a better model than the latter $\left(\mathrm{chi}^{2}=79.75, p=0.000\right)$. That is, there is significant provincial variation in public attitudes about guanxi practices and fairness.

Control variables show systematic variations in attitudes toward guanxi among urban populations. For example, Communist Party members have significantly higher odds of viewing guanxi as unfair, compared with non-Party members. The Communist Party of China strongly opposes guanxi in its official ideology, which would increase its members' tendency to have or proclaim to have negative views on guanxi (Yang 1994). People living in the western region also have higher odds of viewing guanxi as unfair, compared to those living in the eastern region, after controlling for provincial-level marketization scores. This finding is consistent with others indicating that Chinese in the western region have different perceptions of inequality, social mobility, and development than those in other regions (Whyte

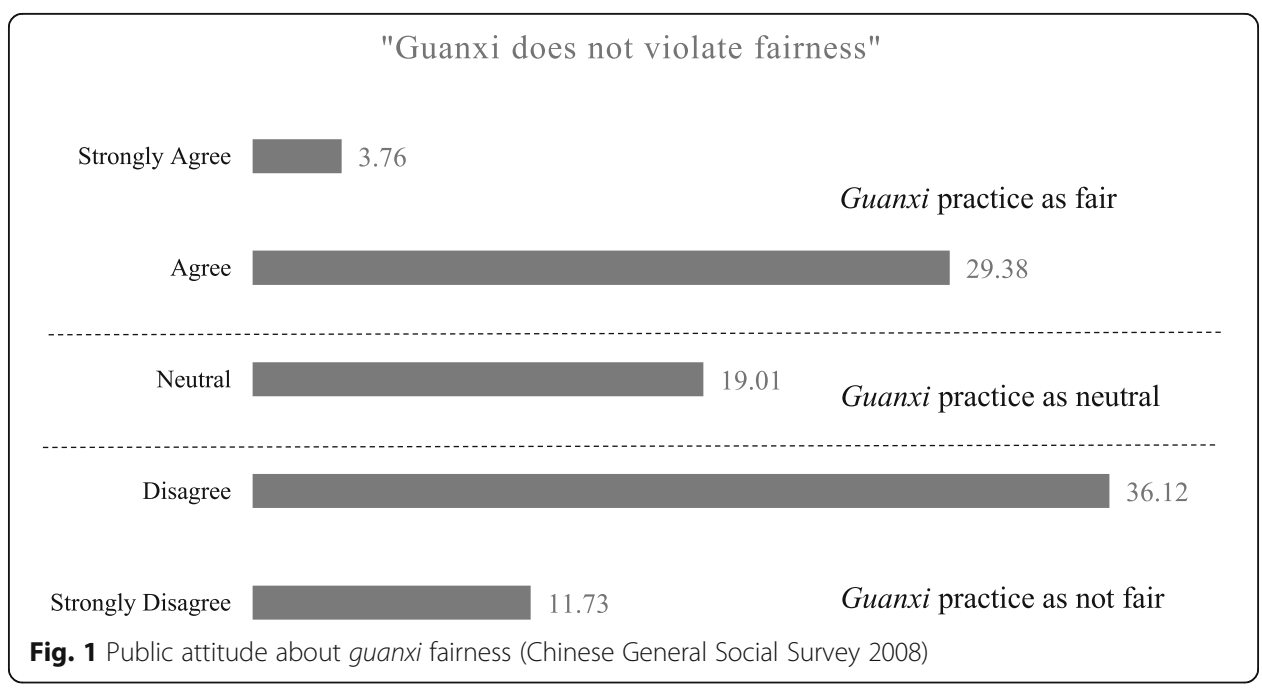


Table 2 Coefficients from multi-level ordinal logistic regressions predicting viewing guanxi as fair, neutral, or unfair (Chinese General Social Survey 2008)

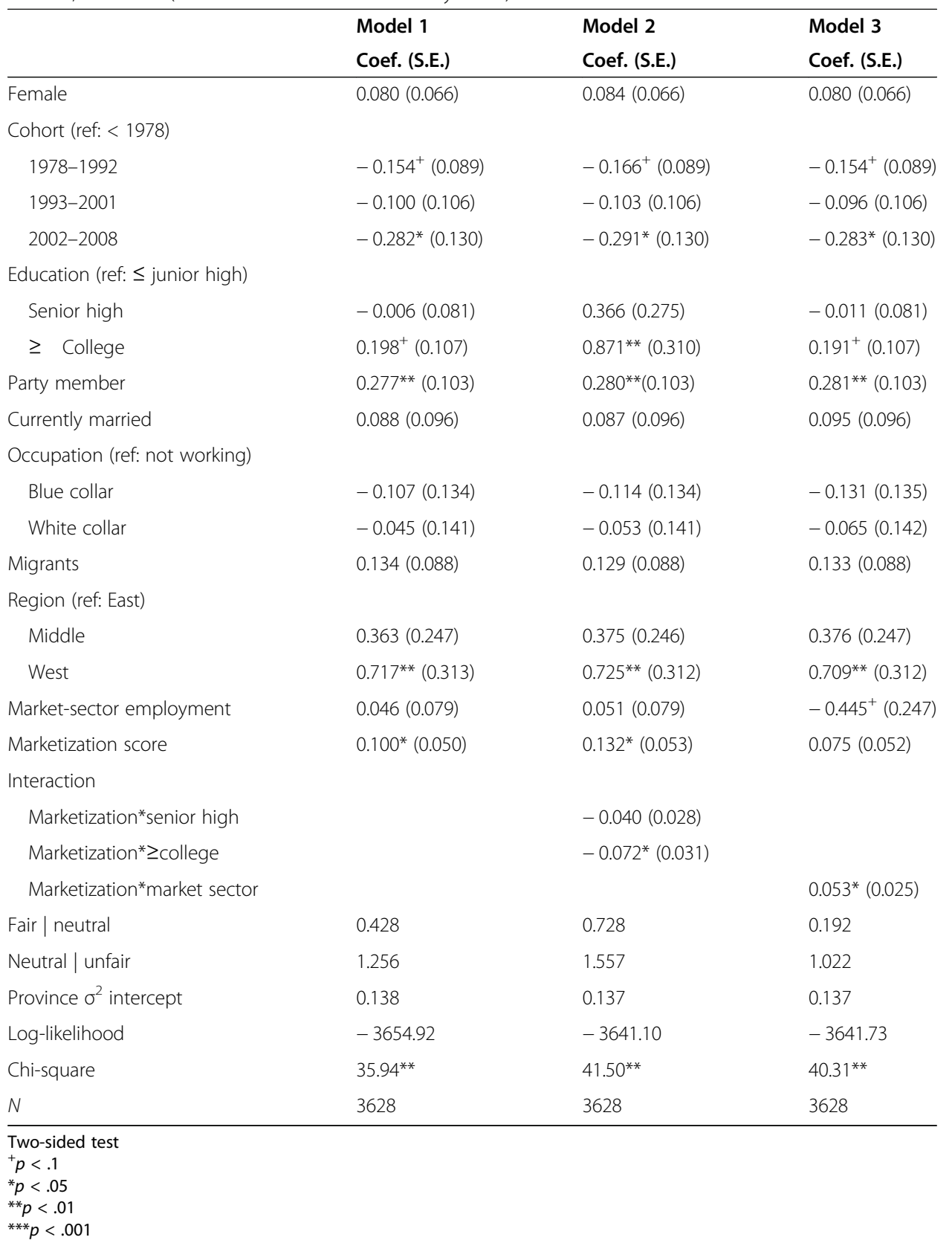

2010; Xie et al. 2012). Surprisingly, the most recent cohort (i.e., those who turned 20 years old in 2002-2008) has more lenient attitudes toward guanxi than previous cohorts. This cohort came of age in a period when guanxi was used pervasively in the Chinese economy (Bian 2018), which may lead them to perceive the practice as legitimate. It is also possible that the most recent cohort legitimizes guanxi because they understand it differently. In this period, the use of weak ties dramatically increased (Tian and Lin 2016) and the meaning of the word guanxi, as anecdotal evidence shows, evolved into a more neutral expression for the concept of networks, called renmai. 
The perception of guanxi as unfair also varies by socioeconomic status, particularly by educational attainment. Those with a college education are significantly more likely to view guanxi as unfair than those whose education stopped at the junior high level or below. This result is expected, as college-educated Chinese tend to endorse meritocracy and equity (Sun 2009). Yet, occupation and migration status are not related to attitudes toward guanxi. Whyte (2010) has shown that the major gap in perceptions of current inequalities is between urban and rural populations. This analysis is primarily based on urban populations, which may not capture the occupational difference in attitudes toward the perceived fairness or unfairness of guanxi. Although migrants may endorse market equity to a greater degree than locals, they also use guanxi extensively in job searches (Lu et al. 2013). This result may help explain migrants' ambiguous attitudes toward guanxi.

Furthermore, the results in model 1 support the prediction that marketization increases public opposition to guanxi (hypothesis 1). The coefficient for the marketization score is positive and significant, indicating a positive relationship between the level of marketization and the likelihood of viewing guanxi as unfair. Specifically, for each unit increase in the marketization score, the odds of viewing guanxi as unfair increase by a factor of $1.104\left(\mathrm{e}^{.099}\right)$. People living in provinces with higher levels of marketization are more likely to view guanxi as unfair.

Models 2 and 3 add interactions to examine whether the association of marketization score and attitudes about guanxi varies by education and employment sector, respectively. Contrary to expectation (hypothesis 2), the interaction coefficient between marketization score and college education (model 2) is negative and significant, indicating that the education gap in the likelihood of viewing guanxi as unfair decreases with levels of marketization. As expected (hypothesis 3), the interaction coefficient between marketization score and market-sector employment (model 3) is positive and significant. The change in attitude about guanxi and fairness is more pronounced among those working in the market sector than those working in the state sector.

Figure 2 illustrates how the education gap in the likelihood of viewing guanxi as unfair changes with marketization score. This gap is based on estimates from model 2 of Table 2, with each control variable set at the main level. When the level of marketization is low (e.g., a score of 3, such as that of Gansu), the probability of viewing guanxi as unfair (versus neutral) differs across education levels: a college education is associated with a $44.7 \%$ probability, a senior high education is associated with a $35.5 \%$ probability, and a junior high or below education is associated with a $30.4 \%$ probability. When marketization is high (e.g., a score of 13 , such as that of Jiangsu), attitudes about guanxi and fairness converge across education groups: all three groups have a predicted probability of roughly $58 \%$ to view guanxi as unfair (versus neutral).

Figure 3 illustrates how the likelihood of viewing guanxi as unfair changes with marketization score between those working in the state sector and those working in the market sector. When the marketization score is low, market-sector workers are less likely than state-sector workers to view guanxi as unfair. For example, at a marketization score of 3 (e.g., Gansu), market-sector workers have a predicted probability of viewing guanxi as unfair of $32 \%$, which is $6 \%$ lower than state-sector workers' predicted probability of $38 \%$. Several studies also show that in the early 


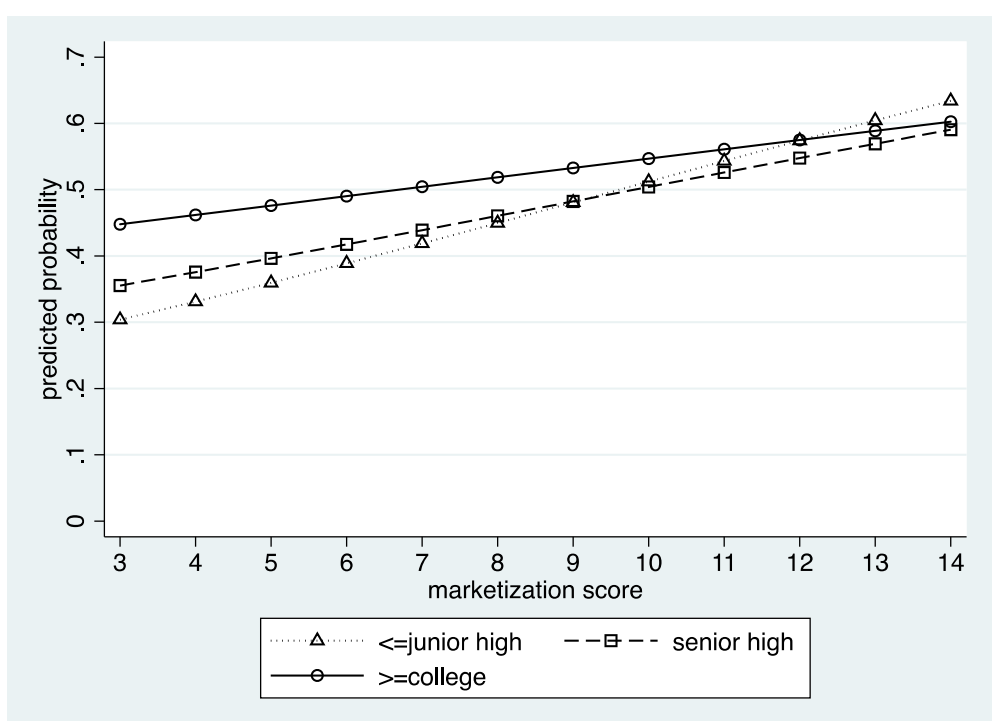

Fig. 2 The predicted probability of viewing guanxi as unfair (versus neutral), by marketization score and educational attainment

phase of the market reform, private entrepreneurs viewed guanxi as crucial to gain information and obtain resources (Nee and Opper 2012; Wank 2001; Yeung and Tung 1996). The two lines tend to cross when the marketization score is between 8 and 9. At a marketization score of 13 (e.g., Jiangsu), the predicted probability of viewing guanxi as unfair is $62 \%$ among market-sector workers and $56 \%$ among state-sector workers, or about $6 \%$ higher in the market sector than in the state sector. Thus, as a market economy grows, the opposition to guanxi grows faster in the market sector than in the state sector.

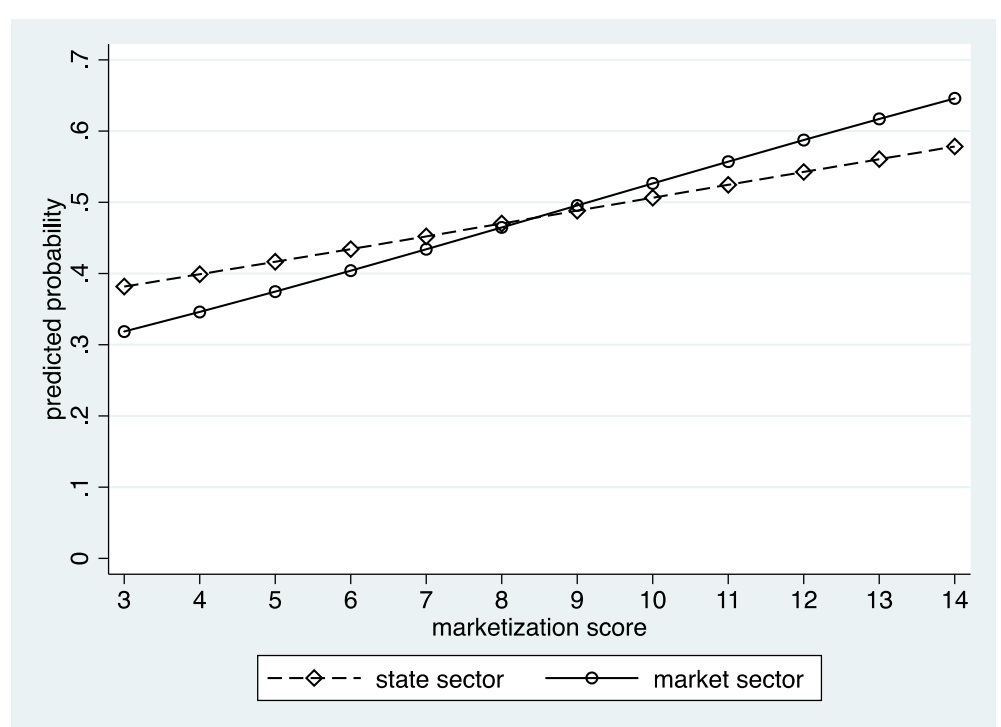

Fig. 3 The predicted probability of viewing guanxi as unfair (versus neutral), by marketization score and employment sector 


\section{Robustness check}

To avoid the possibility that the association found in the paper is a result of a temporary fluctuation in the 2007 scores, I further examine the relationships by using a 5-year average (2004-2008) of the development of the non-state economy. I also replicate the results with Fan et al. (2011) overall marketization score, both for the 2007 score and the 5 -year average. Table 3 presents the results. The coefficients of the 5 -year average of the development of the non-state economy are largely consistent with those of the 2007 score used in Table 2. When using Fan et al.'s (2011) overall marketization score, the pattern of a closing education gap is consistent, and the direction of coefficients for other models is largely consistent. The larger variation in models with overall marketization scores may be due to smaller variations in the overall marketization score (SD = 1.990 in 2007) than the scores for the development of a non-state economy $(\mathrm{SD}=2.622$ in 2007).

\section{Discussion and conclusion}

This article examines public attitudes toward the fairness of guanxi and how these attitudes change with the development of the market economy in urban China. I argue that the transformation from a planned economy to a market economy has shifted public beliefs about fairness toward the equity rule. As Chinese people increasingly believe in efficiency and distribution of rewards based on relative contributions, guanxi, which is reciprocity-bound and tie-sensitive, is increasingly perceived as less legitimate and unfair. The data from the 2008 CGSS support this argument: individuals are more likely to view guanxi as an unfair practice in provinces with a higher level of marketization. This relationship is also moderated by educational attainment and employment sector. As marketization grows, people with different education levels tend to view guanxi's fairness similarly, but those working in the market sector are more affected than those working in the state sector.

The current findings indicate that the gap in attitudes about the fairness of guanxi decreases across education groups as marketization increases. This finding contradicts those of Sun (2009), who has found that people without college degrees still adhere to the equality principle even during market reforms. Whyte and Im (2014) have provided a clue that helps to explain how both findings make sense. They find that in the face of

Table 3 Robustness check

\begin{tabular}{|c|c|c|c|}
\hline & $\begin{array}{l}\text { 2004-2008 marketization } \\
\text { sector }\end{array}$ & $\begin{array}{l}2007 \text { overall } \\
\text { score }\end{array}$ & $\begin{array}{l}\text { 2004-2008 overall } \\
\text { score }\end{array}$ \\
\hline \multicolumn{4}{|l|}{ Model 1} \\
\hline Marketization score & $0.087(0.057)$ & $-0.005(0.102)$ & $0.116(0.112)$ \\
\hline \multicolumn{4}{|l|}{ Model 2} \\
\hline Marketization*senior high & $-0.041(0.029)$ & $-0.081^{*}(0.037)$ & $-0.086^{*}(0.041)$ \\
\hline Marketization ${ }^{*} \geq$ college & $-0.066^{*}(0.032)$ & $-0.087^{*}(0.040)$ & $-0.091 *(0.044)$ \\
\hline \multicolumn{4}{|l|}{ Model 3} \\
\hline $\begin{array}{l}\text { Marketization*market } \\
\text { sector }\end{array}$ & $0.051 *(0.026)$ & $0.049(0.032)$ & $0.056(0.036)$ \\
\hline $\begin{array}{l}\text { Two-sided test } \\
{ }^{+} p<.1 \\
{ }^{*} p<.05 \\
{ }^{* *} p<.01 \\
{ }^{* *} p<.001\end{array}$ & & & \\
\hline
\end{tabular}


rising income inequality, Chinese people show no aggregated resentment toward the rich and successful. Rather, they have a strong desire for the government to provide sufficient welfare to the poor. Thus, the closing education gap makes sense in that Chinese with less education do not want to reverse the equality principle of the socialist era, but rather want the government to remedy the extreme inequality created by the equity principle.

Interestingly, both the use of guanxi and public objection to it have increased during the Chinese market reform era. Theories of culture in action (e.g., DiMaggio 1997; Swidler 1986; Vaisey 2009) demonstrate how culture and actions often do not correspond with each other. Swidler's (1986) well-cited culture-as-toolkit theory indicates that individuals possess several often-contradictory cultural repertoires for actions. These repertoires do not motivate behavior but instead provide justifications for behavior after the fact. Vaisey (2009) has provided a cognitive basis for the motivation-justification distinction. The two processes activate different parts of the brain, such that individuals may offer justifications that are not related to real motives because they feel pressure to provide a reason for their behavior. For example, people who endorse the value that marriage should be based on romantic love should end their romantic relationships as soon as such feelings fade, yet this is often not the case. Cultural repertoires are thus limited in their constraints on actions; rewards and sanctions in the physical and social environments must also be taken into account to explain the behavior (DiMaggio 1997).

Vaisey (2009) has recommended using fixed-response surveys to explore the connections between cultural motives and action, "the types of action-situation profiles that render certain forms of processing more relevant for predicting action" (p. 1706). For example, when examining the choice of neighborhood racial composition, Bruch and Mare (2006) have used vignettes to examine the individual preference for neighborhood racial composition. They showed respondents a series of 5 hypothetical neighborhoods and asked them which of these neighborhoods they would be willing to move into. Thus, to empirically explore the connection between the perception of guanxi and the actual use of it, instead of asking about the fairness of guanxi in abstract terms, future surveys could show respondents several concrete, hypothetical situations-such as job searches or business dealings-and ask them whether they would use guanxi in those situations, or ask them to judge the fairness of guanxi use in such situations.

Some limitations of the paper are worth mentioning here. First, although the robustness check results (Table 3) are consistent, Fan et al. (2011) marketization score is not above criticism. For example, Dong and Hao (2010) suggest that Fan's score is not comparable from year to year, as several components do not use consistent statistics. In addition, the development score of the non-state sector market (used in the main analysis) cannot differentiate private economic development from foreign investment (Shu and Bian 2003). Future research could use more consistent and nuanced indicators to address this question.

Due to the cross-sectional nature of the data, I do not make any causal claims and cannot address the possibility of reverse causation. It is possible that the results cannot entirely be explained by the effect of marketization. It is also possible that public disapproval of guanxi serves as a catalyst for market reforms in these provinces. The current data do not rule out this possibility, but fieldwork on early market reforms shows that reverse causation is not the whole story. In provinces that initiated marketization in the 
early 1980s, guanxi was a vital component for business success and helped protect private entrepreneurs from predatory cadres (Nee and Opper 2012; Peng 2004; Xin and Pearce 1996). The data (Fig. 3) also show that when the marketization level is low, most people working in the market sector view guanxi as fair. Future data using a longitudinal design can help further clarify the causal relationship between public attitudes about guanxi and marketization.

Taken together, these findings contribute to the debate about how guanxi has evolved during the Chinese market reform era. Public disapproval of guanxi increases with marketization and poses additional constraints for its use as an exchange of favors or to obtain illicit services from individuals and organizations. It is unlikely that guanxi will disappear, however. Instead, its meaning and practice in the contemporary Chinese market economy will likely evolve. Burt and Batjargal (2019) have proposed comparative research between China and other countries to help interpret guanxi in relation to social capital. Several studies have answered this call (e.g., Bian and Ang 1997; Lin et al. 2013; Son 2013). More research about public attitudes toward guanxi, especially in a comparative perspective, will facilitate understanding of whether and in which way guanxi is culturally idiosyncratic or congruent with the uses of social capital commonly observed in other societies.

\title{
Abbreviations
}

CGSS: Chinese General Social Survey; CPC: Communist Party of China

\begin{abstract}
Acknowledgements
I thank Xujian Yang for his assistance in data analysis. I also thank Nan Lin, Ronald Burt, Yanjie Bian, Deborah Davis, Elena Obukhova, and Jar-Der Luo for their comments and suggestions. A previous version of this paper was presented at 2016 Chinese Social Networks and Social Capital Section Meeting of Chinese Sociological Association and 2017 Guanxi for Guanxi Study Workshop.
\end{abstract}

Author's contributions

Solo author. Not Applicable. The author read and approved the final manuscript.

\section{Funding}

The work is supported by National Social Science Foundation of China, Fund for Young Scholars, "Community Power Structure, Social Capital Building and Implications for Governance" (19CSH005).

Availability of data and materials

The Chinese General Social Survey is public available at: http://www.cnsda.org/.

\section{Competing interests}

The author is not aware of any affiliations, memberships, funding, or financial holdings that might be perceived as affecting the objectivity of this manuscript.

Received: 4 June 2020 Accepted: 29 October 2020

Published online: 22 December 2020

\section{References}

Alngenberg, Eike A. 2008. Guanxi and business strategy: theory and implications for multinational companies in China. New York: Springer.

Barbalet, Jack. 2014. The structure of Guanxi: resolving problems of network assurance. Theory and Society 43 (4): 51-69. Barbalet, Jack. 2015. Guanxi, tie strength, and network attributes. American Behavioral Scientist 59 (8): 1038-1050.

Berger, Peter L., and Thomas Luckmann. 1966. The social construction of reality: a treatise in the sociology of knowledge. New York: Anchor Books.

Bian, Yanjie. 2002. Institutional holes and job mobility processes: Guanxi mechanisms in China's emergent labor markets. In Social Connections in China: Institutions, Culture, and the Changing Nature of Guanxi, ed. T. Gold, D. Guthrie, and D. Wank, 117-135. New York: Cambridge University Press.

Bian, Yanjie. 2018. The prevalence and the increasing significance of guanxi. China Quarterly 235: 597-621.

Bian, Yanjie, and Soon Ang. 1997. Guanxi networks and job mobility in China and Singapore. Social Forces 75 (3): $981-1005$. Bian, Yanjie, and Xianbi Huang. 2009. Network resources and job mobility in China's transitional economy. In Work and Organizations in China after Thirty Years of Transition, ed. L. Keister, 255-282. Binley: Emerald Group Publishing Limited.

Bian, Yanjie, and Lulu Li. 2012. The Chinese General Social Survey (2003-2008): sample designs and data evaluation. Chinese Sociological Review 45: 70-97.

Bian, Yanjie, and Lei Zhang. 2013. Guanxi culture and guanxi social capital [in Chinese]. Journal of Humanities 1: 107-113. 
Boisot, Max, and John Child. 1996. From fiefs to clans and network capitalism: explaining China's emerging economic order. Administrative Science Quarterly 41 (4): 600-628.

Bramall, Chris. 2009. Chinese economic development. London: Routledge.

Bruch, Elizabeth E., and Robert D. Mare. 2006. Neighborhood Choice and Neighborhood Change. American Journal of Sociology 112 (3): 667709.

Burt, Ronald S., and Bat Batjargal. 2019. Comparative Network Research in China. Management and Organization Review 15 (1): 3-29.

Burt, Ronald S., and Katarzyna Burzynska. 2017. Chinese entrepreneurs, social networks, and guanxi. Management and Organization Review 13 (2): 221-260.

Chang, Kuang-Chi. 2011. A path to understanding guanxi in China's transitional economy: variations on network behavior. Sociological Theory 29 (4): 315-339.

Chen, Chao C., Ya-Ru Chen, and Katerine R. Xin. 2004. Guanxi practice and trust in management: a procedural justice perspective. Organization Science 15 (2): 200-209.

Deutsch, Morton. 1975. Equity, equality and need: what determines which value will be used as the basis of distributive justice? Journal of Social Issues 31 (3): 137-149.

DiMaggio, Paul. 1997. Culture and Cognition. Annual Review of Sociology 23: 263-287.

Dong, Xiaoyu, and Lingyan Hao. 2010. A quantitative study of China's marketization process: the marketization index of last 30 years [In Chinese]. Contemporary Economy and Management 32 (6): 8-13.

Douglas, Mary. 1986. How institutions think. Syracuse: Syracuse University Press.

Dunfee, Thomas W., and Danielle E. Warren. 2001. Is guanxi ethical? A normative analysis of doing business in China. Journal of Business Ethics 32 (3): 191-204.

Ellard, John H., Harvey Annelie, and J. Callan Mitchell. 2016. The justice motive: history, theory, and research. In Handbook of Social Justice Theory and Research, ed. C. Sabbagh and M. Schmitt, 127-143. New York: Springer.

Fan, Gang, Xiaolu Wang, and Hengpeng Zhu. 2011. Chinese marketization index: provincial-level marketization process and 2011 report [in Chinese]. Beijing: Economic Science Press.

Fei, Xiaotong. 1947. From the soil: the foundations of Chinese society, a translation of Fei Xiaotong's Xiangtu Zhongguo. Los Angeles: University of California Press.

Gold, Thomas. 1985. After comradeship: personal relations in China since the cultural revolution. The China Quarterly 104: 657-675.

Greenberg, Jerald, and Ronald L. Cohen. 1982. Why justice? Normative and instrumental interpretations. In Equity and Justice in Social Behavior, ed. J. Greenberg and R.L. Cohen, 437-466. New York: Academic.

Guthrie, Doug. 1998. The declining significance of guanxi in China's economic transition. The China Quarterly 154: 254-282.

Hanser, Amy. 2002. Youth job searches in urban China: the use of social connections in a changing labor market. In Social Connections in China: Institutions, Culture, and the Changing Nature of Guanxi, ed. T. Gold, D. Guthrie, and D. Wank, 137161. New York: Cambridge University Press.

Hsu, Francis L.K. 1953. Americans and Chinese: Two Ways of Life. New York: Henry Schuman.

Huang, Xianbi. 2008. Guanxi networks and job searches in China's emerging labor market: a qualitative investigation. Work, Employment and Society 22: 467-484.

Hwang, Dennis B., Patricia L. Golemon, Yan Chen, Teng-Shih Wang, and Wen-Shai Hung. 2009. Guanxi and business ethics in Confucian society today: an empirical case study in Taiwan. Journal of Business Ethics 89 (2): 235-250.

Hwang, Kwang-kuo. 1987. Face and favor: the Chinese power game. American Journal of Sociology 92 (4): 944-974.

Keister, Lisa. 2002. Guanxi in business groups: social ties and the formation of economic relations. In Social Connections in China: Institutions, Culture, and the Changing Nature of Guanxi, ed. T. Gold, D. Guthrie, and D. Wank, 77-96. New York: Cambridge University Press.

Kluegel, James R., David S. Mason, and Bernd Wegener. 1995. Social justice and political change: public opinion in capitalist and post-communist states. New York: Aldine DeGruyter.

Kohlberg, L. 1981. Essays on Moral Development, Vol. 1: The Philosophy of Moral Development. San Francisco: Harper and Row. Kornai, János. 1992. The Socialist System: The Political Economy of Communism. Princeton: Princeton University Press.

Lerner, Melvin J. 1977. The justice motive: some hypotheses as to its origins and forms. Journal of Personality 45 (1): 1-52.

Li, Tian, and Felicia F. Tian. 2020. Guanxi and job mobility in the socialist transformation. The China Review 20 (2): 183-209.

Lin, Nan, Fu Yang-chinh, and Chih-jou Jay Chen, eds. 2013. Social Capital and Its Institutional Contingency: A Study of the United States, China and Taiwan. New York: Routledge.

Lin, Yi-min. 2002. Beyond dyadic social exchange: guanxi and third-party effects. In Social Connections in China: Institutions, Culture, and the Changing Nature of Guanxi, ed. T. Gold, D. Guthrie, and D. Wank, 57-76. New York: Cambridge University Press.

Lu, Yao, Danching Ruan, and Gina Lai. 2013. Social Capital and Economic Integration of Migrants in Urban China. Social Networks 35 (3): 357-369.

Luo, Jar-Der. 2011. Guanxi revisited: an exploratory study of familiar ties in a Chinese workplace. Management and Organization Review 7 (2): 329-351.

Luo, Yadong, Ying Huang, and Stephanie Lu Wang. 2012. Guanxi and organizational performance: a meta-analysis. Management and Organization Review 8 (1): 139-172.

McClosky, H., and J. Zaller. 1984. The American Ethos: Public Attitudes Toward Capitalism and Democracy. Cambridge: Harvard University Press.

Meng, Tianguang. 2012. Chinese people's perception of distributive justice in transitional China: outcome justice and opportunity justice [in Chinese]. Chinese Journal of Sociology 32 (6): 108-134.

Naughton, Barry. 2006. The Chinese economy: transitions and growth. Cambridge: The MIT Press.

Nee, Victor. 2005. Organizational dynamics of institutional change: politicized capitalism in China. In The Economic Sociology of Capitalism, ed. V. Nee and R. Swedberg, 53-74. Princeton: Princeton University Press.

Nee, Victor, and Sonja Opper. 2010. Political capital in a market economy. Social Forces 88 (5): 2105-2032.

Nee, Victor, and Sonja Opper. 2012. Capitalism from below: markets and institutional change in China. Cambridge: Harvard University Press. 
Nee, Victor, Sonja Opper, and Sonia Wong. 2007. Developmental state and corporate governance in China. Management and Organization Review 3 (1): 19-53.

Obukhova, Elena. 2012. Motivations vs. relevance: using strong ties to find a job in urban China. Social Science Research 41: 570-580.

Obukhova, Elena, and George J. Lan. 2013. Do job seekers benefit from contacts? A direct test with contemporaneous searches. Management Science 59 (10): 2204-2216.

Obukhova, Elena, and Letian Zhang. 2017. Social capital and job search in urban China: the strength-of-strong-ties hypothesis revisited. Chinese Sociological Review 49 (1): 1-22.

Peng, Yusheng. 2004. Kinship networks and entrepreneurs in China's transitional economy. American Journal of Sociology 109 (5): $1045-1074$

Ritzman, Rosemary L., and Donald Tomaskovic-Devey. 1992. Life chances and support for equality and equity as normative and counternormative distribution rules. Social Forces 70 (3): 745-763.

Roller, Edeltraud. 1994. Ideological basis of the market economy: attitudes toward distribution principles and the role of government in Western and Eastern Europe. European Sociological Review 10 (2): 105-117.

Shu, Xiaoling, and Yanjie Bian. 2003. Market Transition and Gender Gap in Earnings in Urban China. Social Forces 81 (4): $1107-$ 1145.

Son, Joonmo. 2013. Social capital and institutional constraints: a comparative analysis of China, Taiwan and the US. New York: Routledge.

Su, Chenting, M. Joseph Sirgy, and James E. Littlefield. 2003. Is guanxi orientation bad, ethically speaking? A study of Chinese enterprises. Journal of Business Ethics 44 (4): 303-312.

Sun, Ming. 2009. Market transition and people's perception of the principles of distributive justice in contemporary China [in Chinese]. Sociological Studies 3: 78-88.

Swidler, Ann. 1986. Culture in action: symbols and strategies. American Sociological Review 51 (2): 273-286.

Tan, Doreen, and Robin Stanley Snell. 2002. The third eye: exploring guanxi and relational morality in the workplace. Journal of Business Ethics 41 (4): 361-384.

Tian, Felicia F., and Nan Lin. 2016. Weak ties, strong ties, and job mobility in urban China. Social Networks 44: 117-129.

Vaisey, Stephen. 2009. Motivation and justification: a dual-process model of culture in action. American Journal of Sociology 114 (6): 1675-1715.

Vogel, Erza F. 1965. From friendship to comradeship: the change in personal relations in communist China. China Quarterly 21: 46-60.

Walder, Andrew. 1986. Communist Neo-traditionalism: work and authority in Chinese industry. Berkeley: University of California Press.

Wank, David. 2001. Commodifying communism: business, trust, and politics in a Chinese city. Cambridge: Cambridge University Press.

Warren, Danielle E., Thomas W. Dunfee, and Naihe Li. 2004. Social exchange in China: the double-edged sword of guanxi. Journal of Business Ethics 55 (4): 353-370.

Whyte, Martin King. 2009. Views of Chinese citizens on current inequalities [in Chinese]. Sociological Studies 1: 91-120.

Whyte, Martin King. 2010. Fair versus unfair: how do Chinese citizens view current inequalities? In Growing Pains: Tensions and Opportunity in China's Transformation, ed. J.C. Oi, S. Rozelle, and X. Zhou, 305-332. Stanford: Shorenstein Center.

Whyte, Martin King, and Dong-Kyun Im. 2014. Is the social volcano still dormant? Trends in Chinese attitudes toward inequality. Social Science Research 48: 62-76.

Xie, Yu, Arland Thornton, Guangzhou Wang, and Qing Lai. 2012. Societal projection: beliefs concerning the relationship between development and inequality in China. Social Science Research 41 (5): 1069-1084.

Xin, Katherine R., and Jone L. Pearce. 1996. Guanxi: connections as substitutes for formal institutional support. The Academy of Management Journal 39 (6): 1641-1658.

Yan, Yunxiang. 1996. The flow of gifts: reciprocity and social networks in a Chinese village. Stanford: Stanford University Press. Yang, Mayfair Mei-hui. 1994. Gift, favors, and banquets: the art of social relationships in China. Ithaca: Cornell University Press.

Yang, Mayfair Mei-hui. 2002. The resilience of guanxi and its new development: a critique of some new guanxi scholarship. China Quarterly 170: 459-476.

Yeung, Irene Y.M., and Rosalie L. Tung. 1996. Achieving business success in Confucian societies: the importance of guanxi (connections). Organization Dynamics (Autumn) 25 (2): 54-63.

Zhang, Shun, and Cheng Cheng. 2012. Market reforms and the income effects of social network capital [in Chinese]. Sociological Studies 1: 130-151.

Zhang, Shun, and Xiaoxian Guo. 2011. A study on social network resources and their effects on income: based on the quantile regression model [in Chinese]. Chinese Journal of Sociology 31 (1): 94-111.

Zhang, Wenhong, and Li Zhang. 2012. Social capital and marketization in the labor market [in Chinese]. Sociological Studies 5: $1-23$.

Zhao, Wei. 2013. Social networks, job search and income disparity in a transitional economy: an institutional embeddedness argument. Research in the Sociology of Work 24: 103-132.

Zuo, Bing. 1997. Face and favor of Chinese people (in Chinese). Wuhan: Central China Normal University.

\section{Publisher's Note}

Springer Nature remains neutral with regard to jurisdictional claims in published maps and institutional affiliations. 